\title{
Physico-chemical Quality Assessment of Palm Kernel Oil During Storage at Room Temperature and Shelter of Light
}

\author{
Gadegbe Afiwa Viviane ${ }^{1, ~ *, ~ B a k o m a ~ B a t o m a y e n a ~}{ }^{1}$, Novidzro Kosi Mawuéna ${ }^{2}$, Dotse Kokouvi \\ Melila Mamatchi ${ }^{2}$
}

${ }^{1}$ Laboratory of Chemistry, Faculty of Health Sciences, University of Lomé, Lomé, Togo

${ }^{2}$ Department of Chemistry, Faculty of Sciences, University of Lomé, Lomé, Togo

Email address:

gadegbev@gmail.com (G. A. Viviane)

${ }^{*}$ Corresponding author

\section{To cite this article:}

Gadegbe Afiwa Viviane, Bakoma Batomayena, Novidzro Kosi Mawuéna, Dotse Kokouvi, Melila Mamatchi. Physico-chemical Quality Assessment of Palm Kernel Oil During Storage at Room Temperature and Shelter of Light. International Journal of Pharmacy and Chemistry. Vol. 5, No. 5, 2019, pp. 52-60. doi: 10.11648/j.ijpc.20190505.12

Received: September 25, 2019; Accepted: October 11, 2019; Published: October 21, 2019

\begin{abstract}
Vegetable oils, including palm kernel oil, are an important part of the human diet. However, traditional methods of storing them often do not take into account changes in quality. In addition, these are food products whose rancidity by autooxidation could affect the health of the consumer. The objective of this work is to evaluate the physico-chemical quality of palm kernel oil during storage at room temperature and away from light. The palm kernel oil samples were collected in plastic containers under strict hygienic conditions, wrapped in aluminium foil and stored at ambient temperature away from light. Physico-chemical parameters were determined for fresh samples and for samples stored after 180 days. The results showed that after 180 days, the oils analysed showed the onset of oxidation. However, the characteristics after 180 days of storage indicate that the oils still have a relatively acceptable quality compared to Codex Alimentarius standards, concomitantly with the high content of saturated fatty acids. Thus, away from light, palm kernel oils could be stored for six months at ambient temperature with a lower risk of rancidity. However, the relative deterioration observed after 180 days of storage requires precautions in the conservation of palm kernel oils produced in Togo.
\end{abstract}

Keywords: Palm Kernel Oil, Storage, Physico-chemical Quality, Auto-oxidation

\section{Introduction}

Vegetable oils are an important part of the human diet as a source of energy, fat-soluble vitamins and essential fatty acids [1]. Palm kernel oil, one of these vegetable oils, is an edible oil obtained from the kernel of the fruit of the Elaeis guineensis and used extensively in developed countries for the formulation of specialty fats, for the manufacture of margarines, creams, candies and other food products. It is also used as a raw material in the production of soaps, detergents and cleaning products and as an emollient for cosmetic and pharmaceutical products [2]. In addition to industrial applications, these oils are used locally as body creams, cooking and medicinal oils, as antidotes against intoxication and as surface protectors for slight injury [3]. In Togo, in addition to an increasingly use for food, palm kernel oil is also used in the cosmetics industry to manufacture soaps and body creams [4]. However, traditional methods of conservation often do not take into account changes in quality. Though, these are food products whose rancidity by auto-oxidation could affect the health of the consumer. In addition to auto-oxidation which is a major cause of oil deterioration during storage, depends on several factors such as the initial composition of the oil, the content of minor compounds with pro- or antioxidant activity (minerals, tocopherols, carotenes, chlorophylls) and storage conditions [5-6]. Autoxidation alters edible oils by degrading fatty acids and thus lowers their nutritional value with the formation of toxic decomposition products [5, 7]. This alteration in oil stability has led researchers to conduct numerous studies on the stability of conventional oils such as olive oil [8-12], sunflower oil [5] and argan oil [13]. Recent year's studies began to investigate the stability of some local oils [6, 14-15] 
but these studies are still insufficient and data for palm kernel oil are still lacking. The susceptibility (stability) of palm kernel oil to oxidation at room storage temperature analysed in this study by monitoring some oxidation markers is a contribution to the recovery of this oil. This study is therefore part of not only food security but also the preservation of the quality of local raw materials for food, cosmetics and pharmacological use in Togo.

\section{Material and Methods}

Study framework

The study was carried out on palm oil produced in the regions of Togo where palm oil production is practiced (Figure 1) and according to the types of production processes, namely traditional and improved processes.

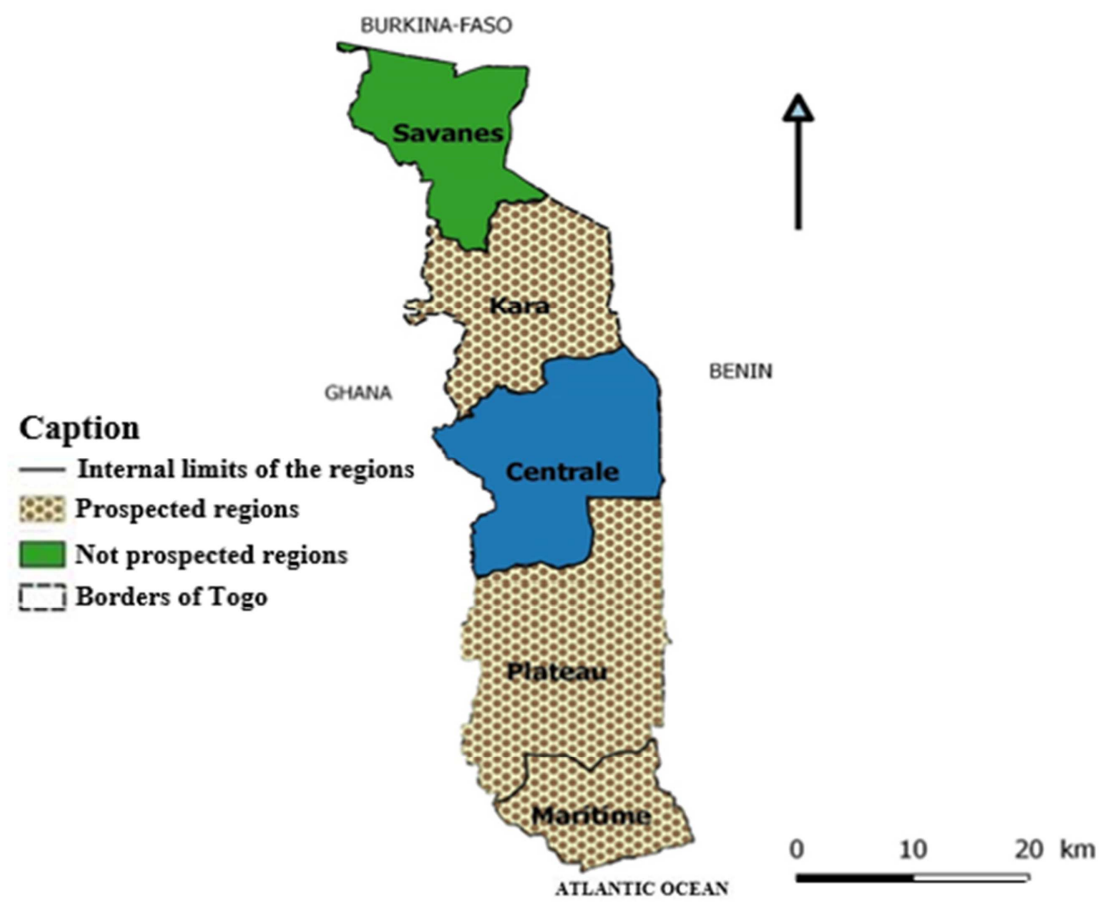

Figure 1. Map of Togo showing the prospected regions.

\section{Sampling}

A total of 36 samples were collected from the production units for analysis.

Most samples were taken either on the day of production or a few days after production. A double sampling was carried out for each type of sample and according to whether it is either the oil collected during the roasting of the almonds, the palm kernel oil for cosmetic, food or therapeutic use.

\section{Experimentation}

Palm kernel oil samples were collected, in duplicate, in plastic containers under strict hygienic conditions, wrapped in aluminium foil and stored at ambient temperature away from light. Some of the samples were analyzed immediately after collection. The remaining samples were kept under the same conditions of analysis after one hundred and eighty days (180 days).

Determination of physico-chemical parameters

The physicochemical parameters were determined using the techniques described in NF T 60-201 standards [16]. For each sample, two tests were performed.

Refractive index

The refractive index of our oil has been determined according to NF T60 - 212 [16].

The refractometer blade was cleaned using Joseph paper, then the apparatus used was calibrated with distilled water with a refractive index of 1.33. A few drops of palm kernel were then placed on the refractometer blade and the dark and light chamber circle was half adjusted. The results were read taking into account the temperature.

Moisture content (water content and volatile matter)

The water and volatile matter (TE) content was carried out under the test conditions specified in standard NF T 60-201 [16]. In a petri dish, $5 \mathrm{~g}$ of palm kernel oil were weighed. The assembly was placed in an oven heated to $105^{\circ} \mathrm{C}$. After one hour, the petri dish was taken out of the oven. It was cooled in the desiccator and then weighed. Then it was put back into the oven for 30 minutes and cooled in the desiccator. This process was repeated until the loss of mass between two weighings was less than $2 \mathrm{mg}$. The results were expressed as follows:

$$
\text { Humidity level }(\%)=\frac{M 1-M 2}{M 1-M 0} \times 100
$$

M0 $=$ mass of the empty petri dish

M1 = mass of the oil-filled petri dish

M2 = mass of the loaded petri dish after drying

Acid value and lauric acidity

The acid value was determined according to NFV 03-906 [16]. In a conical flask, 5 grams of palm kernel oil were 
weighed. To this test sample, $50 \mathrm{ml}$ of ethanol previously neutralized with an ethanolic solution of potassium hydroxide in the presence of phenolphthalein was added and brought to the boiling point. This set was titrated under stirring with the same ethanolic solution of potassium hydroxide in the presence of phenolphthalein. A pink coloration lasting more than ten seconds marks the end of the titration.

*Indice d'acide (mg de $\mathrm{KOH} / \mathrm{g}$ d'huile):

$$
\text { Acid value }=\frac{V \times T}{m} \times 56,1
$$

The acidity was deduced from the acid number and expressed as a percentage of free fatty acids as follows:

*Lauric acidity:

$$
\operatorname{Acidity}(\%)=\frac{V \times T}{10 \times m} \times 200
$$

$\mathrm{V}=$ volume of potassium hydroxide ethanolic solution used for titration

$\mathrm{T}=$ title of the ethanolic solution of potassium hydroxide

$\mathrm{m}=$ mass in grams of the test sample

The number 200 represents the molecular weight of lauric acid.

Peroxide value

It was determined according to the protocol described in NFT 60-220 [17]. The test was carried out in diffuse daylight. In a ground-neck conical flask, 2 grams of palm kernel oil were dissolved in $10 \mathrm{ml}$ of chloroform. To this solution, $15 \mathrm{ml}$ of oxygen-free acetic acid by splashing with nitrogen and $1 \mathrm{ml}$ of potassium iodide solution were successively added. The vial was immediately clogged, the whole thing shaken and placed in a dark place for 5 minutes. Then $75 \mathrm{ml}$ of distilled water was added and the resulting solution was titrated with a $0.1 \mathrm{~N}$ solution of sodium thiosulfate in the presence of starch poison. A blank test was carried out under the same conditions. The expression of the results is as follows:

Peroxide value (meq of $0 \_2 / \mathrm{kg}$ of oil $)=8000 \times \frac{\mathrm{V}}{E} \times \frac{1}{8}$

$\mathrm{V}=$ volume in $\mathrm{ml}$ of the sodium thiosulfate solution used to titrate the test.

$\mathrm{E}=$ mass in grams of the test sample.

Iodine index

It was determined according to the Wijs method described in accordance with the NF standard

$\mathrm{T}$ 60-220 [17]. In $5 \mathrm{ml}$ of chloroform, $3 \mathrm{~g}$ of palm kernel oil was dissolved. Of the solution thus formed, $2 \mathrm{ml}$ was collected and placed in a $250 \mathrm{ml}$ Erlen Meyer. In the latter, 5 $\mathrm{ml}$ of iodine chloride solution was added. The whole was mixed and then left out of the light for one hour, after which $5 \mathrm{ml}$ of potassium iodide solution and $50 \mathrm{ml}$ of distilled water were added. The resulting solution was titrated with an aqueous solution of $0.1 \mathrm{~N}$ sodium thiosulfate in the presence of starch poison. A blank test was carried out under the same conditions.

The expression of the results is as follows:

$$
\begin{aligned}
& \text { Iodine index }\left(m g \text { of } \frac{I_{2}}{100 g}\right) \\
& =12,69 \times \mathrm{T} \times \frac{(V o-V 1)}{m}
\end{aligned}
$$

Vo $=$ volume in $\mathrm{ml}$ of sodium thiosulphate solution used for white

$\mathrm{V} 2$ = volume in $\mathrm{ml}$ of Sodium thiosulphate solution used for the test

$\mathrm{T}=$ exact title of the sodium thiosulphate solution used

$\mathrm{m}=$ mass in grams of the test sample

Saponification index

This parameter was determined according to the protocol described by standard NF T 60-206 [16]. In a conical flask, $25 \mathrm{ml}$ of $0.5 \mathrm{~N}$ potassium hydroxide ethanolic solution was poured into 2 grams of palm kernel oil. The whole was brought to a boil under reflux condenser with slight agitation. After one hour, the heating was stopped and the still hot solution was titrated with a $0.5 \mathrm{~N}$ hydrochloric acid solution in the presence of 5 drops of phenolphthalein. A blank test was carried out under the same conditions. The expression of the results was as follows:

$$
\begin{gathered}
\text { Indice de saponification }\left(\mathrm{mg} \frac{\mathrm{KOH}}{\mathrm{g}}\right) \\
=\frac{(V 0-V 1)}{m} \times T \times 56,1
\end{gathered}
$$

$\mathrm{V} 0=$ volume in $\mathrm{ml}$ of hydrochloric acid solution used for the blank test

$\mathrm{V} 1$ = volume in $\mathrm{ml}$ of hydrochloric acid solution used for the determination

$\mathrm{T}=$ title of the hydrochloric acid solution used

$\mathrm{m}=$ mass in grams of the test sample

Ester index

The index is not measured experimentally, but rather is deduced by differentiating between the Saponification Index $(\operatorname{InS})$ and the Acid Index (InA).

Ester Index $($ EIN $)=$ Saponification Index $($ SIn $)-$ Acid Index (AIn)

\section{Impurety level}

The impurity level was determined according to the protocol described in standard NF T 60-202 [16]. The palm kernel oil has been treated with an excess of solvent and the resulting solution is filtered. The residue remaining on the filter was washed with the same solvent used for oil treatment. The filter was then dried at $103^{\circ} \mathrm{C}$ until a constant mass was obtained. The result was expressed according to the formula below.

$$
\text { Impurities \%. }=\frac{M 1-M 0}{M} \times 100
$$

M0 is the initial mass in grams of the filter vessel 
assembly

M1 is the final mass in grams of the filter vessel assembly

$\mathrm{M}$ is the mass in grams of the test sample

Content of chlorophylls ( $a$ and $b$ ) and total carotenoids

The pigmented phytoconstituents contained in palm kernel oil were quantified under the conditions described by [18], which consist in avoiding as much as possible after extraction, exposure of the oil to light, oxygen and acids. The pigment determination was done by the UV-Visible spectroscopic method [19]. The solution was prepared by introducing $30.25 \mathrm{mg}$ in $10 \mathrm{ml}$ of $100 \%$ Acetone. The resulting mixture was well agitated with a Vortex and the optical density of the solution thus prepared was read at the following three different wavelengths: $1=470 \mathrm{~nm} ; 2=645$ $\mathrm{nm}$ and $3=662 \mathrm{~nm}$ and the spectrophotometer used is of the SHANGHAI METASH UV-5200PC type.

The levels of chlorophyll a (C [a]), chlorophyll b (C [b]) and total carotenoids $(\mathrm{C}[\mathrm{x}+\mathrm{c}])$ were determined using the following trichromatic formulae:

$$
\begin{aligned}
& \text { Chlorophyls a }(\text { Chla })=(11.75 \times \text { A662 })-(2.35 \times \text { A645 }) \\
& \text { Chlorophyls b }(\text { Chlb })=(18.61 \times \text { A645 })-(3.96 \times \text { A662 })
\end{aligned}
$$

The concentrations of carotenoids are deduced by the following formula:

$$
\begin{gathered}
\text { Total carotenoids }\left(\mu \frac{g}{g}\right) \\
=\frac{(1000 \times A 470)-(2,27 \times \text { Chla })-(81,4 \times C h l b)}{227}
\end{gathered}
$$

The results were expressed in $\mu \mathrm{g} / \mathrm{g}$ oil.

Calorific Value

The calorific value (CV) was calculated using the following forrmula [20].

$$
\text { Calorific Value }(\mathrm{KJ} / \mathrm{Kg})=47645-4.187 \mathrm{InI}-38.31 \mathrm{InS}
$$

Where IIn is the iodine index and SIn the saponification index.

\section{Statistical analysis}

The Graph Pad Prism software, version 7.00 was used for statistical data processing. The results were considered as an average plus or minus the standard deviation error (SD). The comparison of the different parameters was carried out by the Student t-Test at the 5\% threshold using the same Graph Pad Prism software, version 7.00. Significant differences were thus considered at the $5 \%$ threshold $(p<0.05)$.

\section{Results}

Variation of the refractive index

Table 1. Refractive index at $D_{0}$ and 180 days $\left(D_{180}\right)$ after storage at ambient temperature.

\begin{tabular}{llll}
\hline & & Types of oil & \\
\cline { 2 - 4 } & & OTP $(\mathbf{n}=\mathbf{1 5})$ & OCRATP $(\mathbf{n}=7)$ \\
\hline \multirow{2}{*}{ Refractive index } & $\mathrm{D}_{0}$ & $1.458 \pm 0.00$ & $1.457 \pm 0,00$ \\
Variation (\%) & $\mathrm{D}_{180}$ & $1.458 \pm 0.00$ & $1.458 \pm 0,00 \quad 1.458 \pm 0.00$ \\
\hline
\end{tabular}

OTP: Oil from the traditional process (it consists in bringing the palm nut marzipan paste to a boil at $100^{\circ} \mathrm{C}$ in the presence of water, after having previously undergone washing and drying, roasting, grinding, crushing or pressing, decantation).

OCRATP: Oil collected during the roasting of almonds in the traditional process.

CPOF: Cold pressed oil used as feed (improved process).

The values are expressed as Mean $\pm \mathrm{SD}$.

The refractive index did not change significantly for all oils considered (Table 1).

Humidity Variation

Table 2. Humidity at $D_{0}$ and 180 days $\left(D_{180}\right)$ after storage at ambient temperature.

\begin{tabular}{lllll}
\hline & & Types of oil & \\
\cline { 2 - 4 } & & OTP (n= 15) & OCRATP (n=7) \\
\hline Humidity (\%) & $\mathrm{D}_{0}$ & $0.31 \pm 0,34$ & $1.04 \pm 0.87$ & CPOF (n = 3) \\
Variation (\%) & $\mathrm{D}_{180}$ & $0.33 \pm 0.38$ & $1.35 \pm 1.05 *$ & $0.08 \pm 0.11$ \\
\hline
\end{tabular}

OTP: Oil from the traditional process (it consists in bringing the palm nut marzipan paste to a boil at $100^{\circ} \mathrm{C}$ in the presence of water, after having previously undergone washing and drying, roasting, grinding, crushing or pressing, decantation).

OCRATP: Oil collected during the roasting of almonds in the traditional process.

CPOF: Cold pressed oil used as feed (improved process).

The values are expressed as Mean $\pm \mathrm{SD}$.

Significantly different from fresh samples: $* \mathrm{P}<0.05 ; * * * \mathrm{P}<0.001$.

The moisture content increased significantly $(\mathrm{P}<0.05)$ after 180 days of storage for the oil collected during the roasting of the almonds and very significantly $(\mathrm{P}<0.001)$ for the oil obtained by cold pressing used for food. However, the variation was not significant for the oil obtained with the traditional process. The percentages of variation were 
respectively, for the oil obtained with the traditional process, that collected during the roasting of the almonds and that obtained by cold pressure used for feeding, of $06.45 \%$,
$29.81 \%$ and $687.50 \%$ (Table 2).

Changes in acid index and lauric acidity Acid index

Table 3. Acid index at $D_{0}$ and 180 days $\left(D_{180}\right)$ after storage at ambient temperature.

\begin{tabular}{|c|c|c|c|c|}
\hline & & \multicolumn{3}{|l|}{ Types of oil } \\
\hline & & OTP $(n=15)$ & $\operatorname{OCRATP}(n=7)$ & CPOF $(n=3)$ \\
\hline \multirow{2}{*}{ Acid index (mg KOH/g) } & $\mathrm{D}_{0}$ & $6.24 \pm 3.04$ & $14.08 \pm 6.89$ & $4.47 \pm 2.28$ \\
\hline & $\mathrm{D}_{180}$ & $7.01 \pm 3.17$ & $17.90 \pm 7.00^{*}$ & $15.77 \pm 12.50 * * *$ \\
\hline Variation (\%) & & 12.34 & 27.13 & 252.79 \\
\hline
\end{tabular}

OTP: Oil from the traditional process (it consists in bringing the palm nut marzipan paste to a boil at $100^{\circ} \mathrm{C}$ in the presence of water, after having previously undergone washing and drying, roasting, grinding, crushing or pressing, decantation).

OCRATP: Oil collected during the roasting of almonds in the traditional process.

CPOF: Cold pressed oil used as feed (improved process).

The values are expressed as Mean \pm SD.

Significantly different from fresh samples: $* \mathrm{P}<0.05 ; * * * \mathrm{P}<0.001$

\section{Lauric acidity}

Table 4. Lauric acidity at $D_{0}$ and 180 days $\left(D_{180}\right)$ after storage at ambient temperature.

\begin{tabular}{|c|c|c|c|c|}
\hline & & \multicolumn{3}{|l|}{ Types of oil } \\
\hline & & OTP $(n=15)$ & $\operatorname{OCRATP}(n=7)$ & $\operatorname{CPOF}(n=3)$ \\
\hline \multirow{2}{*}{ Lauric acidity (\%) } & $\mathrm{D}_{0}$ & $2.22 \pm 1,08$ & $5.02 \pm 2.46$ & $1.59 \pm 0.81$ \\
\hline & $\mathrm{D}_{180}$ & $2.41 \pm 1,14$ & $6.38 \pm 2.49 *$ & $5.62 \pm 4.46^{* * *}$ \\
\hline Variation $(\%)$ & & 8.56 & 27.09 & 253.46 \\
\hline
\end{tabular}

OTP: Oil from the traditional process (it consists in bringing the palm nut marzipan paste to a boil at $100^{\circ} \mathrm{C}$ in the presence of water, after having previously undergone washing and drying, roasting, grinding, crushing or pressing, decantation).

OCRATP: Oil collected during the roasting of almonds in the traditional process.

CPOF: Cold pressed oil used as feed (improved process).

The values are expressed as Mean \pm SD.

Significantly different from fresh samples: $* \mathrm{P}<0.05 ; * * * \mathrm{P}<0.001$.

After 180 days of storage at ambient temperature, the acid value and lauric acidity of the oil obtained with the traditional process did not vary significantly. However, there was a significant increase $(\mathrm{P}<0.05)$ in these two parameters for the oil collected during almond roasting and a very significant increase $(\mathrm{P}<0.001)$ compared to the oil obtained with the cold pressing process (Tables 3 and 4).

Change in the peroxide index

Table 5. Peroxide value at $D_{0}$ and 180 days $\left(D_{180}\right)$ after storage at ambient temperature.

\begin{tabular}{lllll}
\hline & & & \\
& & Types of oil & \\
\cline { 3 - 5 } & & OTP $(\mathbf{n}=\mathbf{1 5})$ & OCRATP $(\mathbf{n}=7)$ & CPOF $(\mathbf{n}=\mathbf{3})$ \\
\hline Index of peroxide $\left(\mathrm{meq}\right.$ of $\left.\mathrm{O}_{2} / \mathrm{Kg}\right)$ & $\mathrm{D}_{0}$ & $0.59 \pm 0.29$ & $0.88 \pm 0.48$ & $2.87 \pm 1.01$ \\
Variation $(\%)$ & $\mathrm{D}_{180}$ & $0.61 \pm 0.32$ & $0.75 \pm 0.22$ & $5.29 \pm 3.08^{* *}$ \\
\hline
\end{tabular}

OTP: Oil from the traditional process (it consists in bringing the palm nut marzipan paste to a boil at $100^{\circ} \mathrm{C}$ in the presence of water, after having previously undergone washing and drying, roasting, grinding, crushing or pressing, decantation).

OCRATP: Oil collected during the roasting of almonds in the traditional process.

CPOF: Cold pressed oil used as feed (improved process).

The values are expressed as Mean \pm SD.

Significantly different from fresh samples: $* \mathrm{P}<0.05 ; * * \mathrm{P}<0.01$.

The peroxide value did not change significantly after 180 days of storage at ambient temperature with the oil samples obtained with the traditional process and that collected during the roasting of the almonds. However, there was a significant increase $(\mathrm{P}<0.01)$ in the peroxide value of the oil obtained with the cold pressure process used for feeding (Table 5).

Change in the iodine index 
Table 6. Iodine index at $D_{0}$ and 180 days $\left(D_{180}\right)$ after storage at ambient temperature.

\begin{tabular}{llll}
\hline & & Types of oil & \\
\cline { 2 - 4 } & & OTP $(\mathbf{n}=\mathbf{1 5})$ & OCRATP $(\mathbf{n}=\mathbf{7})$ \\
\hline \multirow{2}{*}{ Iodine index (mg I/100g) } & $\mathrm{D}_{0}$ & $4.29 \pm 1.28$ & $4.15 \pm 1.38$ \\
Variation (\%) & $\mathrm{D}_{180}$ & $3.78 \pm 1.22$ & $3.33 \pm 0.58$ \\
\hline
\end{tabular}

OTP: Oil from the traditional process (it consists in bringing the palm nut marzipan paste to a boil at $100^{\circ} \mathrm{C}$ in the presence of water, after having previously undergone washing and drying, roasting, grinding, crushing or pressing, decantation).

OCRATP: Oil collected during the roasting of almonds in the traditional process.

CPOF: Cold pressed oil used as feed (improved process).

The values are expressed as Mean $\pm \mathrm{SD}$.

The iodine index decreased in a non-significant way, after 180 days of storage at ambient temperature, for all the oils considered (Table 6).
Changes in saponification index and ester index Saponification index

Table 7. Saponification index at $D_{0}$ and 180 days $\left(D_{180}\right)$ after storage at ambient temperature.

\begin{tabular}{llll}
\hline & & Types of oil & \\
\cline { 3 - 4 } & & OTP (n= 15) & OCRATP (n=7) \\
\hline Saponification index (mg KOH/g) & $\mathrm{D}_{0}$ & $261.90 \pm 1,74$ & $262.90 \pm 3.76$ \\
Variation (\%) & $\mathrm{D}_{180}$ & $261.90 \pm 1,59$ & $263.70 \pm 5.02$ \\
\hline
\end{tabular}

OTP: Oil from the traditional process (it consists in bringing the palm nut marzipan paste to a boil at $100^{\circ} \mathrm{C}$ in the presence of water, after having previously undergone washing and drying, roasting, grinding, crushing or pressing, decantation).

OCRATP: Oil collected during the roasting of almonds in the traditional process.

CPOF: Cold pressed oil used as feed (improved process).

The values are expressed as Mean $\pm \mathrm{SD}$.

\section{Ester index}

Table 8. Ester index at $D_{0}$ and 180 days $\left(D_{180}\right)$ after storage at ambient temperature.

\begin{tabular}{llll}
\hline & & Types of oil & \\
\cline { 2 - 4 } & & OTP $(\mathbf{n}=\mathbf{1 5})$ & OCRATP $(\mathbf{n}=7)$ \\
\hline \multirow{2}{*}{ Ester index $(\mathrm{mg} \mathrm{KOH} / \mathrm{g})$} & $\mathrm{D}_{0}$ & $255.60 \pm 3.96$ & $248.80 \pm 8.48$ \\
Variation $(\%)$ & $\mathrm{D}_{180}$ & $255.11 \pm 4.18$ & $245.79 \pm 10.62$ \\
\hline
\end{tabular}

OTP: Oil from the traditional process (it consists in bringing the palm nut marzipan paste to a boil at $100^{\circ} \mathrm{C}$ in the presence of water, after having previously undergone washing and drying, roasting, grinding, crushing or pressing, decantation).

OCRATP: Oil collected during the roasting of almonds in the traditional process.

CPOF: Cold pressed oil used as feed (improved process).

The values are expressed as Mean $\pm \mathrm{SD}$.

The saponification index did not change after 180 days of storage at ambient temperature for oil obtained with traditional process A. However, this index varied for oil collected during almond roasting by a non-significant increase and for oil obtained by cold pressing by a non- significant decrease (Table 7).

The ester value decreased insignificantly after 180 days of storage at ambient temperature for all oils considered (Table $8)$.

\section{Change in impurity content}

Table 9. Impurity content at $D_{0}$ and 180 days $\left(D_{180}\right)$ after storage at ambient temperature.

\begin{tabular}{lllll}
\hline & & Types of oil & & \\
\cline { 2 - 4 } & & OTP $(\mathbf{n}=\mathbf{1 5})$ & OCRATP $(\mathbf{n}=\mathbf{7})$ & CPOF $(\mathbf{n}=\mathbf{3})$ \\
\hline Impurity content (\%) & $\mathrm{D}_{0}$ & $2.39 \pm 1,17$ & $5.36 \pm 2.65$ & $1.71 \pm 0.87$ \\
Variation (\%) & $\mathrm{D}_{180}$ & $2.59 \pm 1,23$ & $6.81 \pm 2.72^{*}$ & $6.14 \pm 4.92 * * *$ \\
\hline
\end{tabular}

OTP: Oil from the traditional process (it consists in bringing the palm nut marzipan paste to a boil at $100^{\circ} \mathrm{C}$ in the presence of water, after having previously undergone washing and drying, roasting, grinding, crushing or pressing, decantation).

OCRATP: Oil collected during the roasting of almonds in the traditional process.

CPOF: Cold pressed oil used as feed (improved process).

The values are expressed as Mean \pm SD.

Significantly different from fresh samples: $* \mathrm{P}<0.05 ; * * \mathrm{P}<0.001$

The impurity content increased in the oils analysed after storage for 180 days with a significant increase $(\mathrm{P}<0.05)$ for 
the oil collected during almond roasting and a very significant increase $(\mathrm{P}<0.001)$ for the oil obtained by cold pressing (Table 9).
Change in chlorophyll ( $a$ and $b$ ) and total carotenoids content

Table 10. "Chlorophyll a" content at $D_{0}$ and 180 days $\left(D_{180}\right)$ after storage at room temperature.

\begin{tabular}{llll}
\hline & & Types of oil & \\
\cline { 3 - 4 } & & OTP (n= 15) & OCRATP (n=7) \\
\hline \multirow{2}{*}{ Content of "chlorophyll a" $(\mu \mathrm{g} / \mathrm{g})$} & $\mathrm{D}_{0}$ & $49,23 \pm 7,75$ & $42,38 \pm 13,12$ \\
Variation (\%) & $\mathrm{D}_{180}$ & $49,05 \pm 8,71$ & $42,73 \pm 8,32$ \\
\hline
\end{tabular}

OTP: Oil from the traditional process (it consists in bringing the palm nut marzipan paste to a boil at $100^{\circ} \mathrm{C}$ in the presence of water, after having previously undergone washing and drying, roasting, grinding, crushing or pressing, decantation).

OCRATP: Oil collected during the roasting of almonds in the traditional process.

CPOF: Cold pressed oil used as feed (improved process).

The values are expressed as Mean $\pm \mathrm{SD}$.

Table 11. Content of chlorophyll b"at $D_{0}$ and 180 days $\left(D_{180}\right)$ after storage at room temperature.

\begin{tabular}{|c|c|c|c|c|}
\hline & & \multicolumn{3}{|l|}{ Types of oil } \\
\hline & & OTP $(n=15)$ & $\operatorname{OCRATP}(n=7)$ & CPOF $(n=3)$ \\
\hline \multirow{2}{*}{ Content of "chlorophyll b" ( $\mu \mathrm{g} / \mathrm{g})$} & $\mathrm{D}_{0}$ & $54.63 \pm 11.87$ & $43.64 \pm 21.68$ & $42.56 \pm 15.17$ \\
\hline & $\mathrm{D}_{180}$ & $54.65 \pm 13.37$ & $44.19 \pm 28.40$ & $38.06 \pm 16.55$ \\
\hline Variation $(\%)$ & & 0.04 & 1.26 & 10.57 \\
\hline
\end{tabular}

OTP: Oil from the traditional process (it consists in bringing the palm nut marzipan paste to a boil at $100^{\circ} \mathrm{C}$ in the presence of water, after having previously undergone washing and drying, roasting, grinding, crushing or pressing, decantation).

OCRATP: Oil collected during the roasting of almonds in the traditional process.

CPOF: Cold pressed oil used as feed (improved process).

The values are expressed as Mean $\pm \mathrm{SD}$.

Table 12. Carotenoid content at $D_{0}$ and 180 days $\left(D_{180}\right)$ after storage at room temperature.

\begin{tabular}{|c|c|c|c|c|}
\hline & & \multicolumn{3}{|l|}{ Types of oil } \\
\hline & & OTP $(n=15)$ & $\operatorname{OCRATP}(n=7)$ & CPOF $(n=3)$ \\
\hline \multirow{2}{*}{ Carotenoid content $(\mu \mathrm{g} / \mathrm{g})$} & $\mathrm{D}_{0}$ & $2.24 \pm 0.93$ & $3.07 \pm 1.46$ & $3.21 \pm 0.68$ \\
\hline & $\mathrm{D}_{180}$ & $2.21 \pm 1.05$ & $2.97 \pm 2.01$ & $3.34 \pm 0.99$ \\
\hline Variation (\%) & & 5.96 & 7.19 & 4.84 \\
\hline
\end{tabular}

OTP: Oil from the traditional process (it consists in bringing the palm nut marzipan paste to a boil at $100^{\circ} \mathrm{C}$ in the presence of water, after having previously undergone washing and drying, roasting, grinding, crushing or pressing, decantation).

OCRATP: Oil collected during the roasting of almonds in the traditional process.

CPOF: Cold pressed oil used as feed (improved process).

The values are expressed as Mean $\pm \mathrm{SD}$.

Pigment contents did not change significantly for all oils considered.

Indeed, compared to chlorophyll a, the contents decreased only slightly for all types of oil analysed (Table 10) while the contents of chlorophyll $b$ increased slightly for the oil obtained with the traditional process and that collected during the roasting of almonds (Table 11). However, this content has decreased for cold pressed oil intended for feeding (Table 11).

Carotenoid contents decreased very slightly for oil obtained by the traditional process and oil collected during roasting of almonds and increased slightly for oil obtained by cold pressing and intended for food (Table 12).

Change in calorific value

Table 13. Calorific value at $D_{0}$ and 180 days $\left(D_{180}\right)$ after storage at room temperature.

\begin{tabular}{|c|c|c|c|c|}
\hline & & \multicolumn{3}{|l|}{ Types of oil } \\
\hline & & $\operatorname{OTP}(n=15)$ & $\operatorname{OCRATP}(n=7)$ & CPOF $(n=3)$ \\
\hline Calorific value $(\mathrm{KJ} / \mathrm{Kg})$ & $\mathrm{D}_{0}$ & $37596 \pm 68.42$ & $37557 \pm 142.90$ & $37601 \pm 24.70$ \\
\hline Variation $(\%)$ & & 0,00 & 0.07 & 0.29 \\
\hline
\end{tabular}

OTP: Oil from the traditional process (it consists in bringing the palm nut marzipan paste to a boil at $100^{\circ} \mathrm{C}$ in the presence of water, after having previously undergone washing and drying, roasting, grinding, crushing or pressing, decantation).

OCRATP: Oil collected during the roasting of almonds in the traditional process.

CPOF: Cold pressed oil used as feed (improved process).

The values are expressed as Mean $\pm \mathrm{SD}$. 
The calorific value did not change after storage at ambient temperature for 180 days for the oil obtained with the traditional process. However, this power varied slightly for the oil collected during almond roasting and that obtained by cold pressing with a decrease and an increase respectively (Table 13).

Table 14. Quality standards for palm kernel oil according to Codex Alimentarius [27].

\begin{tabular}{ll}
\hline Physicochemical parameters & Standards \\
\hline Refractive index at $40^{\circ} \mathrm{C}$ & $1.448-1.452$ \\
Humidity level at $105^{\circ} \mathrm{C}$ & $<0.2 \% \mathrm{~m} / \mathrm{m}$ \\
Saponification value & $230-254 \mathrm{mg} \mathrm{KOH} / \mathrm{g}$ \\
Iodine value & $14.5-19.5 \mathrm{of} \mathrm{I} / 100 \mathrm{~g}$ \\
Peroxide value & $<15 \mathrm{meq} / \mathrm{kg}$ \\
Acid value & $<4.0 \mathrm{mg} \mathrm{KOH} / \mathrm{g}$ \\
Acidity & $<5 \%$ \\
Impurity rate & $<0.05 \% \mathrm{~m} / \mathrm{m}$ \\
Chlorophyll a and b content & Not available \\
Total carotenoid contents & Not available \\
Calorific Value & $>35000 \mathrm{KJ} / \mathrm{Kg}$ \\
\hline
\end{tabular}

\section{Discussion}

Light and high temperatures are the main causes of oil oxidation $[6,21]$. In this study, these two major conditions favouring the oxidation of oils were eliminated when the oil samples were stored at ambient temperature $\left(26^{\circ} \mathrm{C} \pm 4^{\circ} \mathrm{C}\right)$ and away from light, since light accelerates the rate of oxidation with the formation of unstable hydroperoxides which are transformed into secondary oxidation products: hydrocarbons, aldehydes, ketones and acids [6]. Thus, samples stored in the dark have better oxidative stability during storage.

After 180 days of storage at ambient temperature of the oils, all the parameters studied varied relatively with significant variations observed in humidity, acidity index, lauric acidity, peroxide index and impurity level. These variations, particularly in the peroxide value, concomitantly with the decrease observed in the iodine value for all types of oil analysed, indicate an oxidation of the oils during storage probably caused by exposure to oxygen from the air [21]. This oxidation implies an alteration of these oils. The significant increase in humidity and impurities confirms this alteration by degradation of essential fatty acids, the consequences of which are a decrease in nutritional value and the formation of decomposition products. This oxidation can lead to an undesirable fragrance and flavour, or even a certain toxicity of these oils $[5,7]$.

In addition, triesters can hydrolyze and give partial glycerides and free fatty acids [22-23]. In addition, unsaturated chains react with oxygen from the air to form oxidation products responsible for the rancidity of fats. These two phenomena are the cause of acidification and oxidation of fats [24]. This justifies the increase in lauric acidity and acid number of our palm oils.
Overall, this alteration concerned more the oil obtained by cold pressing. The other oils showed relatively little alteration. It is therefore necessary to identify and control the critical points of this production process, which is considered to be improved. The other parameters studied judging the quality and oxidation state of an oil did not change significantly in this study. This can be justified on the one hand by the fact that palm kernel oil contains few unsaturated fatty acids and on the other hand, by the elimination of major oxidation conditions of oils during storage at ambient temperature and away from light, since high temperatures and light accelerate the auto-oxidation of fats and this alteration is all the more important as the unsaturation of the oil is important $[5,6]$. Light, the source of photo-oxidation of oils, involves the degradation of pigments such as chlorophylls a and $b$ and carotenoids [6, 25]. In this study, the storage of samples in a dark place minimized this photo-oxidation and this explains the small variation in "chlorophyll a" and "b" as well as in total carotenoid levels [11]. Indeed, total chlorophylls and total carotenoids are compounds strongly involved in photooxidation reactions because of their photosensitivity role [12]. During exposure to light, chlorophyll captures the energy from the light which will then be transferred to the oxygen which passes to the excited state (singlet oxygen) then reacting with unsaturated fatty acids, while chlorophyll is reduced [12, 25-26]. The slight variations observed, which still justify the onset of degradation, can then be explained by auto-oxidation, which is predominant when storing oils away from light $[11,26]$.

In addition to these relatively small variations recorded during this study, samples stored for 180 days away from light and at ambient temperature indicated physico-chemical parameters close to or in compliance with Codex Alimentarius standards [27]. This indicates that these are oils that are still good for food quality with similar chlorophyll, carotenoid and calorific capacity to fresh samples. This is due to the good storage conditions and also above all to the low content of unsaturated fatty acids that characterizes palm kernel oil rich in saturated fatty acids.

This result shows that palm kernel oils produced in Togo can be stored for a relatively long period at ambient temperature away from light with a lower risk of rancidity for consumption and use in cosmetics.

\section{Conclusion}

All the results obtained with the physico-chemical tests make it possible to affirm from a stability point of view that palm kernel oils produced in Togo are alterable by autooxidation even in the absence of light. However, the parameters analysed showed that these oils still have a good quality compared to standards and fresh palm kernel oils with a good nutritional value because they are highly calorific with interesting chlorophyll contents. The study of the stability of the palm kernel oils analysed then leads to the 
conclusion that these oils can be stored for six months at ambient temperature if they are kept away from light. This confirms the ability of palm kernel oil produced in Togo to be stored for a relatively long time with a lower risk of rancidity for consumption. However, this oil should be consumed sparingly, as it is rich in saturated fatty acids. However, its use in cosmetics, in combination with other oils of interest is recommended.

\section{References}

[1] FAO (2009): Food and Agriculture Organization of the United Nations. Livestock in the balance. Rome, 180 p.

[2] GIZ (2015): La transformation artisanale dans la filière palmier à huile dans l'espace Taï (Côte d'Ivoire). Rapport d'expertise GIZ-Côte d'Ivoire, 86 p.

[3] Atasie, V. N. and Akinhanmi T. F. (2009): Extraction, Compositional Studies and Physico-Chemical Characteristics of Palm Kernel Oil. Pakistan Journal of Nutrition, 8: 800-803.

[4] Abalo A. (2005): Transformation traditionnelle et commercialisation de l'huile de palmiste, cas de la région maritime. Mémoire de Fin de Cycle; Université de Lomé/Ecole Supérieure d'Agronomie - Ingénieur Agroéconomiste, $61 \mathrm{p}$.

[5] Crapiste G. H., Brevedan M. I. V., Carelli A. A. (1999): Oxidation of sunflower oil during storage. JAOCS, 76 (12): $1437-1443$.

[6] Aboubakar - Dandjouma A. K., Tchiegang C., Parmentier M. (2008): Evolution de quelques paramètres de qualité physicochimique de l'huile de la pulpe des fruits de Canarium schweinfurthii Engl. au cours du stockage. Int. J. Biol. Chem. Sci., 2 (3): 249-257.

[7] Pokorny J. (2003): Problèmes de stabilité des produits alimentaires liés à la présence des lipides. In Lipides et Corps Gras Alimentaires, Graille J (éd). Collection Sciences \& Techniques Agroalimentaires, Editions Tec \& Doc: Paris (France), $470 \mathrm{p}$.

[8] Ben Milled D. D., Smaoui A., Zarrouk M., Chérif A. (2000): Does extraction method affect olive oil quality and stability? Bioch Soc Transactions, 28 (6): 929-933.

[9] Cinquanta L., Esti M., Di Matteo M. (2001): Oxidative stability of virgin oilve oils. JAOCS, 78 (12): 1197-1202.

[10] Okogeri O., Tasioula-Margari M. (2002): Changes occuring in phenolic compounds and -tocopherol of virgin olive oil during storage. J. Agric. Food Chem., 50 (5): 1077-1080.

[11] Psomiadou E., Tsimidou M. (2002a): Stability of virgin olive oil. 1. Autoxydation studies. J. Sci. Food Agric., 41: 640-647.

[12] Psomiadou E., Tsimidou M. (2002b): Stability of virgin olive oil. 2. Photo-oxidation studies. J. Agric. Food Chem., 50: 722-727.

[13] Chimi H., Cillard J., Cillard P. (1994): Autoxydation de l'huile d'argan Argania spinosa L. du Maroc. Sci Alts, 14: 117-124.

[14] Tchiegang - Megueni C. (2003): Variabilité des caractéristiques physico-chimiques des huiles de extraites des amandes Balanites aegyptiaca 1 . del en provenance du Cameroun et du Tchad. Procédé Biologiques alimentaires, 0001, Revue ${ }^{\circ}{ }^{1}$, ISSN 1728-9890.

[15] Adjadji I., Aissi V. M., Ahoussi-Dahouenon E., Akpovo P., Soumanou M. M. (2009): Stabilité de l'huile de coton d'origine béninoise au cours du stockage. Rech. Sci. Univ. Lomé (Togo) série A, 11 (1): 1-10.

[16] AFNOR (1984): Recueil des normes françaises. Corps gras graines oléagineuses, produits dérivés. 3e ed. Paris.

[17] AFNOR (1993): Corps gras, graines oléagineuses, produits dérivés. 5e édition, Paris.

[18] Petry F. C. (2017): Mercadante AZ. New Method for Carotenoid Extraction and Analysis By HPLC-DAD-MS/MS in Freeze-Dried Citrus and Mango Pulps. J. Braz. Chem. Soc., 29 (1): 205-215.

[19] Boutayeb A. (2013): Etude bibliographique sur les huiles essentielles et végétales; Mémoire Online, Université Ibn Tofail. 2013. https://www.memoireonline.com/11/15/9306/Etudebibliographique-sur-les-huiles-essentielles-et-vegetales.html (accessed 16 January 2019).

[20] NOVIDZRO K. M., WOKPOR K., AMOUSSOU F. B., KOUDOUVO K., DOTSE K., OSSEYI E., KOUMAGLO K. H. (2019): Etude de quelques paramètres physicochimiques et analyse des éléments minéraux, des pigments chlorophylliens et caroténoïdes de l'huile de graines de Griffonia simplicifolia. Int. J. Biol. Chem. Sci., 13 (4): 2360-2373.

[21] Tekaya I. B., Hassouna N. (2005): Matière grasse végétale et industries agro-alimentaires. OCL, 12: 447-454.

[22] Wolff J. P. (1991): Analyse et dosage des lipides. In Techniques d'Analyse et de Contrôle dans les Industries Agroalimentaires IV: Analyse des Constituants alimentaires, Multon JL (coordonnateur) (2ème edn). Lavoisier Tec et Doc: Paris (France); $450 \mathrm{p}$.

[23] Poisson J. P., Narce M. (2003): Corps gras alimentaires: aspects chimiques, biochimiques et nutritionnels. In Lipides et Corps Gras Alimentaires, Graille J (éd). Collection Sciences \& Techniques Agroalimentaires, Editions Tec \& Doc: Paris (France), $470 \mathrm{p}$.

[24] Kondratowicz E. P., Ostasz L. (2000): Quality changes in edible oils at high temperature kinetic analysis. Eur. J. Lipid. Sci. Technol. 276-281.

[25] Psomiadou E., Tsimidou M. (2001): Pigments in Greek virgin olive oils: occurrence and levels. J. Agric. Food Chem., 50: 716-721.

[26] Prior E. (2003): Usage des corps gras alimentaires dans les différents secteurs de la technologie alimentaire. In Lipides et corps gras alimentaires, Graille J (éd). Collection Sciences \& Techniques Agroalimentaires, Editions Tec \& Doc: Paris (France); $470 \mathrm{p}$.

[27] Codex Alimentarius (1999): http://www.fao.org/fao-whocodexalimentarius/shproxy/en/?lnk=1\&url=https $\% 253 \mathrm{~A} \% 252$ F\%252Fworkspace.fao.org\%252Fsites\%252Fcodex\%252FSta ndards\%252FCODEX\%2BSTAN\%2B2101999\%252FCXS_210f.pdf (accessed 20 December 2018). 